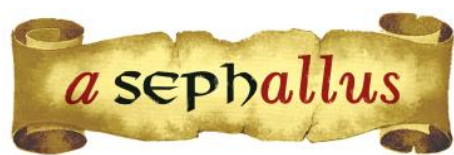

Revista aSEPHallus de Orientação Lacaniana

Núcleo Sephora de Pesquisa sobre o Moderno e o Contemporâneo

ISSN $1809-709 \mathrm{X}$

\title{
A era do desvelamento e a função do véu
}

Ariana Moura Gomes

Psicanalista

Psicóloga pela Universidade Federal do Paraná / UFPR (Paraná, Brasil)

Mestranda pela Universidade Federal do Rio de Janeiro / UFRJ (Rio de Janeiro, Brasil)

Email: ariana.moura@gmail.com

Resumo: Encontramo-nos, na atualidade, imersos em uma sociedade que confere cada vez mais importância às imagens - como podemos verificar nas áreas da segurança, da comunicação, da saúde, dentre outras. Atribuímos tal predominância da imagem à ascensão do discurso da ciência, que propõe que tudo o que é real pode ser conhecido, e, para isso, visto. A este momento atual, centrado na visibilidade, Wajcman o nomeia, em determinado momento de seu livro L'Oeil Absolu, de a "Era do desvelamento". O presente artigo busca investigar as implicações dessa nomeação, buscando para isso a elucidação do conceito de véu como proposto por Lacan. $O$ objetivo de tal percurso seria o de encontrar recursos para pensar em que termos podemos explicar, pelo ponto de vista psicanalítico, a sociedade centrada no apelo à visibilidade como a identificamos. Palavras-chave: imagem; discurso da ciência; véu; fetichismo.

\section{The age of unveiling and the veil's function}

We find ourselves, nowadays, immersed in a society which grants more and more importance to images - as we can verify in the fields of security, communication, health, just to mention a few. We attribute this prominence of the image to the rise of science's discourse, which proposes that everything can be known, and for that matter, seen. This present time, focused in visibility, is named by Wajcman as "the age of unveiling". The present article investigates the implications in this nomination, thus searching to enlighten the concept of veil as proposed by Lacan. The main goal of the present study is to find resources to think in which terms we can explain, from a psychoanalytical point of view, society's focus on visibility as it has been identified.

Key-words: image; science's discourse; veil; fetichism.

\section{L'age du dévoilement et la fonction du voile}

Nous nous trouvons de nos jours immergés dans une société qui attribue de plus en plus d'importance aux images - ceci peut être vérifié dans plusieurs domaines, tels que la sécurité, la communication et la santé, pour en citer quelques uns. Nous associons cette proéminence de l'image à l'avènement du discours de la Science qui propose que tout peut être connu et donc vu. Cette actualité centrée sur la visibilité, Wajcman la nomme, a un moment donné de son ouvrage "L'Oeil Absolu", "L'age du dévoilement". Cet article investigue les implications de cette nomination, cherchant pour cette raison a élucider le concept de voile tel qu'il fut proposé par Lacan. Le but de ce parcours étant de trouver des ressources pour réfléchir aux termes par lesquels nous pouvons expliquer, du point de vue psychanalytique, la société centrée sur Is visibilité telle que nous l'avons identifiée.

Mots-clés: image; discours de la Science; voile; fétichisme. 


\title{
A era do desvelamento e a função do véu
}

\author{
Ariana Moura Gomes
}

Encontramo-nos, na atualidade, diante de uma inegável ascensão da importância atribuída às imagens em nossa sociedade. Vemos o uso das imagens como um meio de comunicação privilegiado, como instrumento de garantia da segurança pública, como objeto do desenvolvimento da tecnologia, como índice da verdade.

Atribui-se tal relevância da imagem à ascensão do discurso da ciência, o qual, através do desenvolvimento tecnológico, encontra recursos para exprimir-se da forma como hoje o encontramos, centrado no apelo à visibilidade. Assumimos como base a hipótese de que o apelo às imagens seria decorrente da faceta totalizante do discurso da ciência, que propõe que tudo o que existe pode ser conhecido, e, nesse contexto, visto. Tal reposicionamento do valor da imagem através do discurso da ciência trouxe consequências nos mais diversos campos da experiência humana, como no campo da segurança pública, da política, da tecnologia, da medicina, da teologia, da economia, apenas para mencionar alguns. O que nos interessa particularmente, no entanto, é analisar o impacto subjetivo de tal ideologia da visibilidade, determinadas particularidades desta convocação a tudo ver, avaliando como ela modifica a relação dos sujeitos com a realidade e com a própria subjetividade.

Partiremos, portanto, da apreciação das razões pelas quais podemos atribuir à ascensão do discurso da ciência o apelo à visibilidade como o verificamos. Para tanto, tomaremos como uma referência privilegiada a obra de Wajcman, intitulada L'Oeil Absolu, que trata de tal tema. Posteriormente, nos deteremos na análise de um termo específico utilizado pelo referido autor como uma definição de nossos tempos atuais - estaríamos, segundo ele, vivendo uma "Era do desvelamento" (Wajcman, 2002, p. 246). Mas o que poderia significar isso?

Tal termo nos capturou a atenção, uma vez que podemos daí presumir que o autor referese ao conceito de véu como formulado por Lacan. Para compreendermos a pertinência de tal nomeação, pretendemos então fazer uma breve revisão do conceito de véu, buscando sublinhar algumas características que possam nos auxiliar em nossa análise.

A proposta do presente artigo centra-se, portanto, não somente na exposição da hipótese de que nossa sociedade se encontra em vias de tornar-se cada vez mais centrada no apelo às imagens em razão do discurso da ciência, mas também verificar em que medida o conceito de véu pode vir em nosso auxílio para compreender os limites do que se esconde e do que se dá a ver nos dias atuais. Portanto, a partir de tal percurso proposto, se impõe a questão: podemos definir nosso momento atual como uma Era do desvelamento, no sentido pleno do termo véu?

\section{A era do desvelamento}


Passemos a uma consideração mais pormenorizada dos fenômenos aos quais nos referimos. Como havíamos mencionado, a relevância da imagem em nossa sociedade hoje tem se elevado consideravelmente. Vivemos um momento no qual o desenvolvimento de diversas tecnologias se voltou à produção de imagens - câmeras, televisões, ressonâncias magnéticas, celulares, computadores, drones. Por todas as partes somos cercados por câmeras, sejam as de vigilância, sejam as televisivas, tendo cada passo gravado por um olho que tudo vê. É o espírito de nosso tempo.

Como afirma Wajcman (2010, p. 13), "A extensão do domínio do olhar decorre da escalada do discurso da ciência. É um fato. Este seria um efeito deletério de sua irresistível ascensão"1. A relatada ascensão da visibilidade seria, portanto, na opinião deste autor, um efeito colateral da ascensão do discurso da ciência, com sua pretensão de compreender a totalidade dos fenômenos do mundo por meio de seu método.

Vemos, na história do pensamento científico, determinados aspectos que se sobressaem daquilo que se define por ciência. Nos centraremos, mais particularmente, em dois desses aspectos: a objetificação e a totalização. Por objetificação compreendemos a exclusão da subjetividade exigida pelo discurso da ciência - a subjetividade do cientista, por exemplo, não deve aparecer em momento algum no que ele enuncia sobre determinada matéria. Tal exclusão acarreta consequências para as possibilidades de formação da subjetividade em nossa sociedade.

Como elucida Milner (1996, p. 29), a hipótese do sujeito da ciência se constitui pela suposição de que a ciência moderna, por ser ciência e por ser moderna, determina um modo particular de constituição de sujeito. A ciência parte da matematização - proposta por Galileu -, que busca extrair um dado puro para análise, excluindo as características particulares dos fenômenos. Os sujeitos, sob a ótica da ciência, são também despojados de suas particularidades e objetificados para análise. O Cogito cartesiano parte deste mesmo princípio: não são as particularidades dos pensamentos possíveis que importa, mas sim o dado puro de que existe o pensamento, o mínimo comum entre todas as possibilidades particulares de pensamento, para desse pensamento concluir a existência de um sujeito. Kant segue a mesma tradição da ciência galileana com o conceito de $a$ priori, e assim por diante. O essencial é delimitar a unidade mínima objetiva universal e separá-la do contingencial, do particular e do patológico.

Outra característica marcante de nossa tradição científica, como afirmamos, é a pretensão de apreender a realidade em sua totalidade. Nada estaria para além dos limites do que a ciência é capaz de compreender e sistematizar, pois, os fenômenos inexplicáveis são apenas uma limitação de tempo, não de método. O projeto racionalista do iluminismo se propunha a expandir a ciência como método de abordagem da realidade e de intervenção no mundo, inclusive na organização política. Os Estados deveriam seguir um ordenamento racional, laico e científico. Nossa sociedade hoje é baseada nesses mesmos princípios, e deles recolhemos os fatos que observaremos neste artigo, tomados como consequências do desenvolvimento de tal ideário. 
A organização de nossa sociedade é baseada nesses mesmos princípios, mas nossa forma de assimilar tais aspectos do discurso da ciência foram se transformando ao longo do tempo, até culminarem em uma sociedade da visibilidade. Há uma diferença entre, por exemplo, a sociedade vitoriana - que fazia segredo para simular encaixar o patológico nos moldes estreitos da racionalidade científica, ainda em estado nascente -, e nossa sociedade atual, que se constitui por uma outra via de abordagem ao imperativo iluminista de tudo expor, tudo examinar em plena luz. Nossa sociedade tornou-se uma máquina de fazer ver. "Tudo ver, tudo visível. Esta é a crença seminal do mundo hipermoderno" (Wajcman, 2010, p. 14)2.

A medida da verdade torna-se aquilo que é visível. Passamos a considerar o desenvolvimento de nossa capacidade de ver em detalhes um mecanismo qualquer como a medida do alcance de nossa compreensão e controle. A medicina exemplifica tal argumento com precisão quando vemos a produção de equipamentos de exames por imagem cada vez mais avançados ser associada à possível compreensão final sobre o funcionamento do cérebro, por exemplo, para com isso promover uma compreensão fisiologista do que constituiria a subjetividade.

O olhar da medicina avança no sentido de objetivar o corpo de sujeitos diversos a tal ponto que a subjetividade se exclua, e a tal ponto que o que seja visado seja um corpo genérico, indiferenciado. Este é um dos cernes do discurso da ciência - a objetificação do sujeito a ponto de desconsiderar a opacidade da subjetividade, como existência singular não totalizável e como cisão que resulta em um resto incompreensível para o próprio sujeito. A ciência busca excluir, rejeitar a existência dessa opacidade irredutível.

A ciência busca excluir a opacidade do sujeito e tratar apenas do que pode ser visto, compreendido e manipulável por ela. Através das tecnologias médicas a ciência não só busca compreender o funcionamento do organismo, mas, ainda, oferecer dispositivos de alerta em caso de risco a ele. Dessa forma, vemos a medicina aproximando-se da lógica da vigilância em prol da segurança. $O$ discurso da ciência promete alcançar, com seu método, meios para bem sinalizar o perigo e lidar com ele da forma comprovadamente mais efetiva, constituindo-se como uma espécie de sistema de alerta análogo ao funcionamento da angústia, compreendida como sinal de perigo. 0 controle técnico das adversidades é incentivado, neste sentido, como um aplacador da angústia decorrente de ameaças antes incontroláveis. As tecnologias voltadas para a expansão da visibilidade, como o vídeo monitoramento, teriam, portanto, a função de constituir um sistema de alerta.

A segurança é talvez a preocupação política paradigmática de nossos tempos. A onipresença das câmeras de vigilância é justificada pelo apelo à segurança num mundo cada vez mais globalizado, onde se tem uma maior circulação de pessoas. No entanto, a ameaça pode vir de dentro das próprias fronteiras nacionais, em meio à tal circulação difusa. A vigilância nos coloca no estranho impasse de, apesar de qualquer desconforto que cause, coadunar com ela em nome da segurança. $O$ terrorismo, como fantasia da grande fonte de ameaça à segurança nacional em diversos países, fez nos últimos 
anos com que se justificasse a intensificação de tal vigilância, de tal forma que nos entregamos a ela como um efeito colateral inevitável da globalização.

A comparação de nossa sociedade atual com a prisão panóptica de Foucault, ou talvez com uma atualização dela, não seria injustificada. A quantidade de câmeras espalhadas pelas cidades são provas físicas de uma vigilância extrema e crescente, e o terrorismo é talvez a justificativa última de tornar permanente uma abordagem de exceção a todos - todos considerados potenciais exceções, todos presumivelmente culpados por delitos ainda por vir.

Semelhante ao olhar da Medusa, tal vigilância nos petrifica e nos altera como sujeitos. Ao descer das alturas, a ideia de um olhar onisciente e onipresente é hoje perpetuada a seu modo pelo discurso da ciência e da tecnologia. Diferentemente do que fora dito sobre a vigilância de Deus, esses olhos não são mais transcendentes, vindos das alturas. Eles são, hoje, a expressão do olhar da sociedade voltado para si mesma. O observador não é mais o observador panóptico, escondido em um ponto cego, vendo a todos e não sendo visto. $\mathrm{O}$ observador agora somos todos nós, bem como somos todos nós os observados que, em nome do direito de observar, consentem com o olhar.

A partir da primazia do imperativo de que tudo deve ser visto, do consentimento contraditório dos sujeitos em fazerem-se vistos, encontramos razões para considerar a hipótese de estarmos hoje vivendo uma sociedade voyeurista e exibicionista. Nos tornamos voyeurs que, subjugados tão absolutamente ao imperativo da vigilância, também nos expomos como objeto do olhar alheio. Ao mesmo tempo em que nos deixamos ser observados por medo, vivenciamos também um estranho gozo neste ato.

Estamos diante de uma atitude à primeira vista contraditória, comum de nossos tempos no cenário descrito, nessa busca por tudo ver que redunda em um consentimento forçado de deixarse ver em nome da segurança e do avanço da ciência, temos, por um lado, uma inquietação paranoica diante desse saber-se observado, mas, por outro, um gozo com o fazer-se ver frente a uma plateia sempre presente.

Os corpos são transformados em espetáculo, em nome da ciência e do entretenimento. Vemos atualmente uma profusão de reality shows, de fotos em redes sociais, programas de TV que mostram microcâmeras navegando no interior dos corpos, devassando a interioridade como se fosse esse o garante de uma melhor divulgação ao público dos avanços das pesquisas. No entanto, o devassamento nunca é suficiente, pois ele se revela como um princípio, criando uma demanda de exposição que nunca se satisfaz.

Seria impossível transitar por este tema sem trazer à memória o advento das "selfies" autorretratos fotográficos produzidos à exaustão. Há uma repetição em série deste ato de fotografar a si mesmo, e, até, de fotografar-se fotografando a si mesmo. O que nos parece estar na origem desses atos é uma relação muito frágil com a própria existência, que precisa ser assegurada através de uma imagem produzida e reproduzida constantemente, aos moldes das expectativas de um público virtual que, com seu olhar, provê algum contorno a essa existência. 
Ocorre uma coincidência do ato de ver e de ser visto, e uma multiplicação das variações na conjugação desta díade - ver, ser visto, se ver sendo visto, ser visto sendo visto por outros. É como se houvesse uma espécie de delegação ao Outro do direito de vê-lo integralmente, agindo como se fosse esse o preço a pagar pela garantia de sua existência e da revelação de si como verdade. É particularmente relevante observar o quanto se busca constantemente se exibir ao olhar do outro como garantia de sua existência. O Cogito poderia ser aqui parafraseado para algo como "sou visto, logo existo", e tal olhar seria buscado incessantemente, como um reasseguramento. Se existe na medida em que é visto, e o não ser visto comumente dispara uma angústia referente a um sentimento de desaparecimento, que deve ser combatido como uma luta pela própria vida.

Em suma, parece que estamos frente à busca de tomarmos a imagem como instrumento de uma revelação totalizante da realidade, que geraria uma segurança impossível. Em nome desse projeto paga-se um preço alto demais, uma vez que busca-se expor tudo o que não esteja ainda visualizado, excluindo a sombra de onde justamente pode advir alguma subjetividade.

Estamos na era do desvelamento. O véu teria sido removido no afã do imperativo da ciência de tudo ver. Em prol de melhor compreendermos, então, o que seria esta era do desvelamento proposta por Wajcman, sugerimos, agora, fazermos um retorno ao conceito de véu, como o encontramos em Freud e Lacan.

\section{A função do véu}

"Pode-se mesmo dizer que com a presença da cortina, aquilo que está mais além, como falta, tende a se realizar como imagem. Sobre o véu, pinta-se a ausência" (Lacan, 1954-1955/2010, p. 157)

Podemos encontrar uma ocorrência inicial da questão do véu na obra de Lacan em seu segundo Seminário, mais especificamente no texto "Do pequeno ao grande outro" (Lacan, 19541955/2010). O véu surge, neste momento, em conjunção com a formulação de que o desejo é tributário da relação de um ser com a falta, e o véu já se prenuncia aqui como espécie de suporte a essa falta: "Esta falta acha-se para além de tudo aquilo que possa apresentá-la. Ela nunca é apresentada senão como um reflexo num véu" (Lacan, 1954-1955/2010, p. 281). Veremos que tal função será teoricamente aprofundada e problematizada posteriormente, ao longo de outras obras.

No Seminário denominado A relação de objeto (1956-1957/1995), Lacan propõe, para melhor elucidar tal conceito, um esquema para o véu. Por meio do exemplo do fetichismo, ele estabelece o véu como a tela na qual se materializará uma imagem que represente a falta que está justamente coberta por tal tela. É o que ocorre na construção do objeto fetiche - tal objeto é essa imagem paradoxal, que representa aquilo que ao mesmo tempo oculta.

Podemos dizer que o objeto fetiche é o que melhor exemplifica o conceito de véu, ou, ainda, que o véu é o que permite explicar qual seria, afinal, o segredo do objeto fetiche. Utilizaremos, 
portanto, o fetichismo para falar do véu e veremos, enfim, que tal aproximação não se dará sem razão no contexto de nossa análise.

Durante o Seminário 4, vemos o fetichismo e a fobia serem apresentados como as categorias clínicas eleitas para desenvolver a argumentação de Lacan a respeito das relações de objeto. Segundo Miller (2002, p. 262), vemos que nesta obra de Lacan encontramos respaldo para considerarmos que ambos - o fetichismo e a fobia - presidem também a configuração da teoria lacaniana acerca da função fálica. Adiantando-nos no texto, vemos, por fim, o autor afirmar que a perversão é a estrutura clínica que parece apontar a verdadeira natureza do falo. Partiremos já deste ponto e verificaremos que as razões que são apontadas para tal afirmativa encontram-se relacionadas justamente ao recurso do véu, à forma que ele é utilizado na criação do objeto fetiche.

Façamos um resumo brevíssimo do que Lacan nos reporta sobre o fetichismo no supracitado Seminário. O fetichismo é uma categoria clínica do campo das perversões, e, como tal, fundamentase na renegação da castração. Frente à constatação da diferença sexual anatômica entre os sexos, a partir da compreensão de que a mãe não tem um pênis, o fetichista renegaria tal percepção através da formação de um objeto substituto ao falo materno.

Nesse ponto reside uma sutileza a respeito do que está sendo formulado sobre o falo, que Miller busca chamar a atenção. Muito haveria sido dito sobre o falo a partir do dispositivo do Nomedo-Pai, o que oblitera o significado primordial do falo, que é o de ser um semblante que desde o início encontra-se primeiro do lado da mãe, para que então ela abra a via para a metáfora paterna.

A essência do falo é ser um semblante, nos alerta o autor, e devemos buscar essa compreensão a partir da castração materna. A questão colocada pela constatação de que a mãe não tem um pênis não é tanto a de faltar algo imaginariamente ao corpo dela, mas o de estabelecer o falo como um índice da presença de uma falta, como o paradigma do que vêm a ser a falta a ser.

O fetichismo surge como uma resposta do sujeito ao deparar-se com o falo como falta a ser, e o véu é o recurso utilizado para isso. Podemos tomar, a título de definição, que "o fetichismo lacaniano é uma imagem projetada sobre o véu que oculta a falta a ser" (Miller, 2002, p. 263).

Detenhamo-nos no funcionamento do véu. Algumas características do véu são, à primeira vista, contraditórias - como parece contraditória a posição perversa da renegação, que rechaça a percepção de algo que irremediavelmente percebeu. Os paradoxos do véu parecem estar intimamente relacionados a esse paradoxo fundante da estrutura perversa.

Em primeiro lugar, o véu busca esconder a falta a ser, ao mesmo tempo em que materializa no objeto fetiche uma representação dessa falta mesma. Nas palavras de Freud (1927/1996, p. 157), ao mesmo tempo que o fetiche se propõe a ser o indício do triunfo sobre a castração, ele é também um monumento erguido em seu nome e como prova de sua ocorrência.

Como afirma Lacan (1956-1957/1995, p. 157), o véu é o ídolo da ausência. Ele funciona como uma tela, interposta entre o sujeito e a falta, sobre a qual é projetada uma imagem, o objeto fetiche, com a promessa de com isso obturar o vazio da falta. Visualizamos, portanto, esse primeiro 
paradoxo: na imagem projetada o objeto pode assumir o lugar da ausência, enquanto a ausência pode ser presentificada através do objeto. Como bem expressa Wajcman (2010, p. 248), o véu, ao mesmo tempo que encobre uma falta, ele cria a presença de algo, dessa imagem que é o objeto fetiche. Ele é um ato criador justamente porque cria essa imagem da falta a ser, que é o falo enquanto semblante.

Por esse motivo também seu efeito é igualmente paradoxal, pois, uma vez que é um ato de criação, ele atrai e fixa o olhar nesta criação. Podemos comparar com o ato de cobrir o corpo feminino, que, por mais que cubra, serve também para sinalizar que algo está por baixo dos panos. Tal exemplo é oportuno se considerarmos que costumeiramente os objetos fetiche são objetos que se relacionam com a dubiedade entre esconder e mostrar, e se ligam intimamente com aquilo que é escondido, como lingeries, protetores de sexo, sapatos, objetos relacionados a partes do corpo.

Isso se dá, como vemos já em Freud (1927/1996), uma vez que, na eleição da imagem específica a ser projetada no véu como objeto fetiche, tal imagem é uma espécie de cena congelada, extraída de um instante anterior ao momento fatídico da constatação da castração. Essa imagem concentra, portanto, em si, um estado dúbio de desconhecimento, reconhecimento e renegação da castração, um equilíbrio delicado que o fetichismo sustenta. Como observa Wajcman (2010, p. 187), só se esconde aquilo que se reconhece. O fetiche é, portanto, a positivação do reconhecimento de uma negatividade, e a tentativa de tamponamento dessa negatividade pela manipulação dessa representação positiva. A estratégia fetichista nesse sentido é radicalmente diferente da fóbica. Enquanto o fóbico busca fugir do confronto com a falta a ser, o fetichista fixa o olhar nessa imagem dúbia pintada sobre o véu.

A respeito ainda dessa dimensão histórica daquilo que é projetado sobre o véu, duas observações devem ser feitas. Primeiro, que a cena congelada se fixa ali como um ponto de referência do momento de parada, indicando que a história onde tal cena se insere continua para além do véu. A segunda, a semelhança que podemos tratar com a memória encobridora freudiana, como retoma Lacan. Ambos os tópicos remetem à mesma questão: a da projeção do simbólico sobre o imaginário.

Temos no campo da perversão uma preponderância da imagem. A tese fundamental de Lacan a respeito da perversão, neste momento, como nos indica Miller (2002, p. 275), é que o que ocorre nela é uma projeção de um encadeamento simbólico no imaginário. Voltemos ao exemplo fornecido por Freud em seu texto sobre o fetichismo, de 1927. Freud relata um caso clínico em que o objeto fetiche de seu paciente era um brilho no nariz, que somente ele conseguia bem distinguir. Freud, ao longo da análise, reconhece que o que está por trás de tal brilho no nariz é uma determinada frase, na língua materna do paciente, que foneticamente lembrava o termo "brilho do nariz" em alemão. Tal frase é a articulação significante à qual nos referimos, que está sempre na base do funcionamento do fantasma. 
Devemos levar em consideração as dimensões simbólica e imaginária do fantasma. A dimensão imaginária é constituída por uma produção profícua de imagens, costumeiramente de conteúdos perversos no caso dos neuróticos. Se decantarmos dela o essencial, tais cenas reduzemse a uma espécie de fórmula, de frase, que é um encadeamento simbólico que fora velado e que provê a temática das cenas. Uma imagem fantasmática é função da articulação simbólica que ela vela para o próprio sujeito (Miller, 2002, p. 267). O que o perverso projeta no véu é uma tradução imaginária dessa articulação significante que a embasa, ou, dito de outra forma, uma projeção do simbólico sobre o eixo imaginário.

Em suma, vemos que o que está colocado em questão na prevalência das imagens fantasmáticas cujo suporte é o véu, é a existência de uma articulação significante sobre a falta, articulação que lhes fornece a base e da qual elas são semblantes. O véu estampa um símbolo, que seria, enfim, uma captura imaginária da articulação simbólica sobre a relação do sujeito com a falta.

\section{Conclusão}

Retomaremos agora nossa análise do momento que nos encontramos na atualidade. Partimos da constatação de que nossa sociedade está essencialmente centrada na imagem, e da hipótese de estarmos no que podemos chamar de a "Era do desvelamento". Precisamos, para isso, nos reencontrar com apontamentos do que podemos compreender do véu como um conceito lacaniano, e assim verificar os possíveis significados de tal diagnóstico.

Como vimos, o véu é um conceito encontrado no contexto da teoria lacaniana acerca da relação de objeto, desenvolvido, mais especificamente, através do exemplo do fetichismo. Ele seria um recurso utilizado pelo sujeito como mediação entre ele a falta a ser, constatada a partir da castração materna. A castração materna, por sua vez, seria o ponto de onde podemos extrair a natureza de semblante do falo como índice da falta a ser. A falta a ser constatada remete o sujeito à questão do que deseja o Outro, ou do que o Outro deseja de mim. Che vuol?

A imagem projetada no véu aplaca a angústia de tal confrontamento. Ela é um símbolo de uma captura imaginária da articulação significante da relação do sujeito com a falta, de forma a dar a essa relação algum contorno fantasmático. Sabemos que o fantasma neurótico é fundamentalmente perverso. O campo da perversão é também, nesse sentido, o campo privilegiado das imagens, das relações imaginárias nos quais o sujeito vem representar sua relação com o objeto $a$, objeto causa do desejo.

Vamos retornar a Wajcman para observar ao que o autor se refere, precisamente, de uma era de desvelamento. $\mathrm{O}$ autor faz uma retomada da nudez nos mitos gregos, bem como na tradição bíblica e, enfim, na produção de obras de arte renascentistas e impressionistas. Em linhas gerais, na antiguidade, tínhamos a nudez sagrada de Diana sendo revelada por acidente e sendo seu expectador, Acteon, punido por seu olhar. Na Bíblia, temos através do pecado primevo o desvelamento do olhar de Adão e Eva sobre sua própria nudez, que somente torna-se por eles 
percebida através da vergonha. Na produção pictórica da renascença, temos um primeiro momento em que uma imagem de uma mulher nua sai do âmbito privado para tornar-se exposta como arte, apesar de tal nudez exposta estar coberta por véus e símbolos que a recobrem com certo pudor. Num salto para a obra impressionista de Manet, Olympia, vemos a nudez ser exposta sem nada que a recubra, uma nudez pura que encara o expectador e o acossa fazendo-o ver aquilo que ele não gostaria de ver, justamente porque desejava demais ver.

E então chegamos em nosso estado atual de relação com a nudez, onde se busca uma nudez mais nua que a própria nudez, um olhar sobre a nudez sem pudor, sem desconforto, sem transgressão. $O$ discurso da ciência promove o olhar e a exibição da nudez no sentido concreto e metafórico, como a consumação de seu projeto racionalista. Não seria mais uma transgressão desnudar e dessacralizar o mundo, mas sim a expressão da maior conformidade com o espírito de nosso tempo cientificista.

As imagens desnudadas tornam-se, elas mesmas, objetos com vida própria, índices de que estaríamos no caminho certo para a compreensão totalizante da verdade. Podemos seguir a linha argumentativa de que ocorre uma fetichização das imagens que venham a representar o ápice de nossa capacidade de revelar a realidade. A rã transparente de Hiroshima, citada por Wajcman (2010, p. 22), seria um desses fetiches da hipermodernidade. Essas imagens parecem encarnar o máximo do desnudamento, o desvelamento último da realidade. Mas não seria esse um engodo?

Essa é nossa hipótese a partir do percurso realizado neste presente artigo. A busca de nossa sociedade em produzir imagens em profusão, sem nenhuma consideração pelo pudor ou pela sacralidade, não seria a produção de uma imagem pura do mundo, sem véu algum. Ela seria sim, talvez, ainda mais bem-sucedida do que anteriormente fora em construir a ideia de que aquela imagem projetada sobre o véu é tudo o que existe, que ela é soberana em nossa relação com a realidade, que não existe nada que esteja por trás dela, esse nada que não pode ser objetificado pela ciência.

O discurso da ciência promoveria, portanto, a formação dessas imagens, atraindo nossa atenção para elas. Além disso, ele dissimula que essas imagens não são pintadas sobre um véu, uma vez que todo pudor teria sido retirado. Ao contrário, elas seriam a imagem da revelação do que estava por trás do véu, as figuras reais que antes só víamos como sombras em nossa caverna. Talvez seja esta uma das ilusões supremas de nosso tempo. A cortina não foi levantada porque a cortina é tudo que existe - o que não existe são as formas eternas, às quais alcançaríamos por meio da consecução final do método da ciência. Estamos lidando com um refinamento da ilusão, e a conclusão controversa à qual chegamos é que a ilusão reside na proposta da ciência, e não no véu.

Por trás do véu permanece o nada, um vazio inobservável, opaco, de onde justamente pode advir a subjetividade. $O$ discurso da ciência não consegue abarcar em seu escopo a subjetividade, pois ela, por definição não pode ser objetivada sem deixar de existir. Não pode ser totalmente 
exposta a luz, ela é um resto que resiste. O véu não foi retirado, só se pintou sobre ele uma imagem feita para dizer que ele o foi.

\section{Notas:}

${ }^{1}$ No original: "L'extension du domaine du regard suit la montée du discours de la science. C'est un fait. Ce serait un effet délétère de son irrésistible ascension" Wajcman (2010, p. 13).

${ }^{2}$ No original: "Tout voir, tout visible. C'est la croyance séminale du monde hypermoderne" (Wajcman, 2010, p. 14).

\section{Referências Bibliográficas}

Freud, S. (1996). Fetichismo. In J. Salomão (Trad.) Edição standard brasileira das obras psicológicas completas de Sigmund Freud (Vol. 21, pp. 151-162). Rio de Janeiro: Imago (Trabalho original publicado em 1927).

Lacan, J. (2010). O seminário, livro 2: o eu na teoria de Freud e na técnica da psicanálise. Rio de Janeiro: Zahar (Trabalho original publicado em 1954-1955).

Lacan, J. (1995). O seminário, livro 4: a relação de objeto. Rio de Janeiro: Zahar (Trabalho original publicado em 1956-1957).

Miller, J.-A. (2002). De la naturaleza de los semblantes. Buenos Aires: Paidós.

Milner, J. C. (1996). A obra clara. Rio de janeiro: Zahar.

Wajcman, G. (2010). L'Oeil Absolu. Paris: Denoël.

Citacão/Citation: Gomes, A. M. (mai. a out. 2015). A era do desvelamento e a função do véu. Revista aSEPHallus de Orientação Lacaniana, 10(20), 39-49. Disponível em www.isepol.com/asephallus. doi: 10.17852/1809-709x.2019v10n20p39-49

Editor do artigo: Tania Coelho dos Santos.

Recebido/Received: 25/08/2015 / 08/25/2015.

Aceito/Accepted: 02/09/2015 / 09/02/2015.

Copyright: (C) 2013 Associação Núcleo Sephora de Pesquisa sobre o moderno e o contemporâneo. Este é um artigo de livre acesso, que permite uso irrestrito, distribuição e reprodução em qualquer meio, desde que o autor e a fonte sejam citados/This is an open-access article, which permites unrestricted use, distribution, and reproduction in any medium, provided the author and source are credited. 